\title{
Mycobacterium Strain and Type of Resistance in Pulmonary Tuberculosis Patients: A Missed Link in Iran's National Tuberculosis Plan
}

\author{
Behnam Honarvar ${ }^{1,}$; Mohsen Moghadami ${ }^{2}$; Amir Emami ${ }^{3}$; Abbas Behzad Behbahani ${ }^{4}$; \\ Mohammad Taheri ${ }^{5}$; Amir Roudgari ${ }^{6}$; Golnar Sami Kashkoli ${ }^{5}$; Mohsen Rezaee ${ }^{7}$; Ehsan \\ Farzanfar ${ }^{6}$; Zahra Zaree ${ }^{5}$; Jamalodin Goharnejad ${ }^{6}$; Fatemeh Khavandegaran ${ }^{7}$; Kamran \\ Bagheri Lankarani ${ }^{1}$ \\ ${ }^{1}$ Health Policy Research Center, Shiraz University of Medical Sciences, Shiraz, IR Iran \\ ${ }_{3}^{2}$ HIV/AIDS Research Center, Shiraz University of Medical Sciences, Shiraz, IR Iran \\ ${ }_{3}^{3}$ Bactriology and Virology Department, Shiraz Medical School, Shiraz University of Medical Sciences, Shiraz, IR Iran \\ ${ }_{5}^{4}$ Diagnostic Laboratory Sciences and Technology Research Center, School of Paramedical Sciences, Shiraz University of Medical Sciences, Shiraz, IR Iran \\ ${ }_{6}^{5}$ Central Microbiology Laboratory, Shiraz Health Center, Shiraz University of Medical Sciences, Shiraz, IR Iran \\ ${ }^{6}$ Shiraz University of Medical Sciences, Shiraz, IR Iran \\ ${ }^{7}$ Shiraz Health Center, Shiraz University of Medical Sciences, Shiraz, IR Iran \\ *Corresponding Author: Behnam Honarvar, Health Policy Research Center, Shiraz University of Medical Sciences, Shiraz, IR Iran. Tel/Fax:+98-7132309615, E-mail: honarvarbh32@yahoo.com \\ Received: February 6, 2015; Revised: April 12, 2015; Accepted: July 11, 2015
}

\begin{abstract}
Background: The Incidence of multi-drug resistant tuberculosis (MDR-TB) is constantly increasing.
Objectives: This study aimed to clarify an important missed link in Iran's national TB plan.

Patients and Methods: Through a 9-month period, all pulmonary TB patients diagnosed based on the national TB protocol, in Shiraz TB center, were selected and culture of TB colonies, drug susceptibility testing (DST), polymerase chain reaction (PCR) for detection of IS6110 gene, Isoniazid (INH) and Rifampin (RIF) tuberculosis resistance were done to collect data. Data were analyzed using SPSS.

Results: In 92 included patients, (mean age $45.4 \pm 15$ years), DST results showed that 16 cases (17.4\%) were resistant to INH,19 (20.7\%) to RIF and $24(26.1 \%)$ to both INH and RIF. Polymerase chain reaction identified IS6110 gene in 71 cases (77.2\%) and gene mutations in $3(3.2 \%)$ KatG, 3(3. 2\%) InhA, 9 (9.7\%) both KatG and InhA, 17 (18.4\%) rpoB and 20 (21.7\%) in KatG, InhA and rpoB genes. Patients with INH-resistant tuberculosis were more than those with RIF-resistant $(\mathrm{OR}=7.1)$.

Conclusions: Findings of the present study show that 4 out of five new cases of pulmonary TB patients who were diagnosed based on the national TB protocol (clinical symptoms and acid fast bacilli staining) had IS6110 gene(MTB, Mycobactrium TB) and at least one-fifth of this group had A kind of Drug Resistant TB. Therefore, by using PCR, as a complementary test, it could be possible to start 1st line anti-TB drugs for only MTB cases (up to $77 \%$ of the patients) and 2nd line drugs for MDR cases ( $15 \%$ of cases). This policy aims to achieve safety and better outcome for patients while saving human and financial resources in health care system.
\end{abstract}

Keywords: Tuberculosis; Drug Resistant; Gene; PCR

\section{Background}

Despite political, economic, research, and community efforts, Tuberculosis (TB) remains one of the world's deadliest communicable diseases (1). In 2013, an estimated 9.0 million people developed TB and 1.5 million died from the disease (2). Also, an incidence rate of TB reported in Iran is 21 cases per 100,000 people (3).

An important challenge in TB control is the emergence of resistant strains to the most potent anti-TB drugs (4). Multidrug Resistant Tuberculosis (MDR-TB), is caused by mycobactria isolates which are resistant to, at least, Isoniazid (INH) and, Rifampin (RIF) (5, 6). Delayed diagnosis and inappropriate treatment of tuberculosis may result in constantly increasing severity, mortality, spreading and the emergence of MDR-TB (7-9). Annually, MDR-TB is estimated to afflict 490,000 cases, or $5 \%$ of the global TB burden. This appears to be a big challenge to TB control due to its complex diagnostic and treatment problem $(10,11)$.

On the other hand, successful control of TB and achievement of third Millennium Development Goals (MDGs) for elimination of TB by 2050 depends on the extent of timely diagnosis of patients with TB and their successful treatment (12). Therefore, early and rapid detection of multidrug resistance is a global priority and is essential for efficient treatment and control of Mycobacterium TB (MTB) (13). IS6110 is an insertion sequence specific to Mycobactrium TB which can be used to differentiate MTB species from other mycobacteria (14). 
Isoniazid resistance is mostly associated with increased risk of treatment failures and acquiring new drug resistance $(15,16)$. Isoniazid enters the bacterial cell wall as a prodrug and is converted to a toxic substance in the cell by a catalase peroxides encoded by a KatG gene. Any mutation in this gene can confer bacterial resistance to isoniazid $(17,18)$.

Also, InhA is a part of a very long chain fatty acid, mycolic acids, in elongation system whose products represent catalysis in the last step of fatty acid elongation. Any mutation in InhA sequences makes changes in INH target and makes the bacteria resistant to isoniazid $(19,20)$.

Rifampin, as an anti TB drug, was introduced in 1972 and showed excellent sterilizing activity. It acts by binding to the $\beta$-subunit of RNA polymerase $(r p o B)(5)$, the responsible enzyme for transcription and expression of mycobacterial genes, inhibits the bacterial transcription activity and results in killing the organism. Any mutation in the 81-bp core region of $r p o B$ was reported to be responsible for drug resistance in at least $95 \%$ of the isolates $(21,22)$.

Using molecular methods for identification of mutations in the genes may offer means for rapid screening of the drug resistance among the MTB isolates and initiation of early treatment $(23,24)$.

\section{Objectives}

The aim of this study was to determine the prevalence of MTB among patients who were diagnosed based on the national TB program (clinical symptoms and Acid Fast Bacilli sputum smear staining) and were treated routinely as pulmonary $\mathrm{TB}$.

Also, this study aimed to detect different patterns of drug resistance, including MDR-TB among these patients to show the ratio of patients that should not be treated as $\mathrm{TB}$ and ratio of patients that must be treated as MDR-TB from the onset of diagnosis. Risk factors associated with resistant patterns were also examined in this study.

\section{Patients and Methods}

\subsection{Setting}

This molecular study comprised of 92 new cases (from December 2012 to August 2013) who were diagnosed based on clinical symptoms and Acid Fast Bacilli (AFB) staining and planned to be treated as pulmonary TB at TB referral centers affiliated to Shiraz University of Medical Sciences, south of Iran. Demographic data for each patient was obtained from the national TB-registry system.

\subsection{Acid Fast Bacilli Staining and Culture on Solid Media}

Concentrated sediment of sputum samples were collected from all patients as follows: Sputum samples were liquefied and decontaminated with $\mathrm{N}$-acetyl cysteine-2.5\%, Sodium Hydroxide (NAOH) and concentrated by centrifugation at $3000 \mathrm{rpm}$ for 20 minutes (10). The sediment was used to inoculate onto a Lowenstein-Jensen (LJ) medium. Inoculated media were incubated at $37^{\circ} \mathrm{C}$ for 8 weeks and examined weekly for colony formation.

\subsection{Niacin Accumulation and Nitrate Reduction Test}

Niacin test was carried out on suspected buff colonies cultured for 6 weeks. Then Niacin positive colonies were used for nitrate reduction test (25).

\subsection{Drug Susceptibility Testing}

For this purpose, colonies of MTB were taken from the surface of the LJ slant. Drug susceptibility testing(DST) was performed using INH (0.2 mg/L. Sigma-Aldrich) and RIF(40 $\mathrm{mg} /$ L. Sigma-Aldrich) according to the proportion method of Canetti (12). For each set of DST, a known MDR strain was used as positive control and H37Rv strain provided by Tehran mycobacteriology research center as negative control.

\subsection{DNA Preparation}

The DNA was extracted from colonies with QIAamp DNA mini kit (QIAgen, Inc., Valencia, California, and USA) according to the manufacturer's instruction. The extracted DNAs were stored at $-70^{\circ} \mathrm{C}$.

\subsection{IS6110 Detection}

Polymerase chain reaction (PCR) was performed on extracted DNAs using specific primers TB1 (5/-ATC CTG CGA GCG TAG GCG TCG G-3/) and TB2 (5/-CAG GAC CAC GAT CGC TGA TCC GG-3/) for a $190 \mathrm{bp}$ fragment. Polymerase chain reaction was performed in a total volume of $50 \mu \mathrm{L}$ reaction mix of $5 \mu \mathrm{L}$ PCR buffer (10x-Qiagene Inc.), $1.5 \mu \mathrm{L} \mathrm{MgCl}_{2}$ (50 mM-Qiagene Inc.), $1 \mu \mathrm{L}$ Deoxynucleotide triphosphates (dNTPs) (0.2 mM-Qiagen, Inc.), 1.5 U Taq DNA polymerase (Qiagen, Inc.) and $1 \mu \mathrm{L}$ of each primer $(10 \mathrm{pmol} / \mu \mathrm{L})$ with $5 \mu \mathrm{L}$ of template. Nuclease free sterile double distilled water was added to a final volume of $50 \mu \mathrm{L}$. The mixture was amplified using thermo cycler program including 10 minutes at $95^{\circ} \mathrm{C}$ for initial denaturation, followed by the PCR condition at $94^{\circ} \mathrm{C}$ for 45 second, $65^{\circ} \mathrm{C}$ for $1 \mathrm{~min}$ and $72^{\circ} \mathrm{C}$ for 45 seconds, for 35 cycles with final extension at $72^{\circ} \mathrm{C}$ for 10 minutes. The PCR products were run on $2 \%$ agarose gel electrophoresis, and visualized after staining with ethidium bromide.

\subsection{Molecular Detection of Rifampin Resistance}

In this study, a multiplex PCR was performed to detect mutation in $r p o B$ region in all positive IS6110 gene samples using the following sets of primers: rpoB516 (5/-CAGCTGAGCCAATTCATGGA-3/), rpoB526 (5/-CTGTCGGGGTTGACCCA-3/), rpoB531(5/ CACAAGCGCCGACTGTC-3/) and RIRm (5-TTGACCCGCGCGTACAC-3) for 218bp, $185 \mathrm{bp}$, and $170 \mathrm{bp}$ fragments, respectively. Polymerase chain reaction was done in a total volume of $25 \mu \mathrm{L}$ reaction mix containing $2.5 \mu \mathrm{L}$ PCR buffer (10x-Qiagene Inc.), $4 \mu \mathrm{L} \mathrm{MgCl} 2$ (5.5 mM-Qiagene Inc.), $1 \mu \mathrm{L}$ dNTPs (0.2 
mM-Qiagen, Inc.), 1.5 U Taq DNA polymerase (Qiagen, Inc.) and $1 \mu \mathrm{L}$ of each primer $(10 \mathrm{pmol} / \mu \mathrm{L})$ with $5 \mu \mathrm{L}$ of template. Nuclease free sterile double distilled water was added to a final volume of $25 \mu \mathrm{L}$. The mixture was amplified with the following thermo cycler program: 5 minutes at $95^{\circ} \mathrm{C}$ for initial denaturation, followed by the PCR condition at $95^{\circ} \mathrm{C}$ for 30 seconds, $68^{\circ} \mathrm{C}$ for 30 seconds and $72^{\circ} \mathrm{C}$ for 30 seconds, for 40 cycles with the 10 minutes final extension at $72^{\circ} \mathrm{C}$. The PCR products were examined for banding patterns by $8 \%$ poly acrylamide gel electrophoresis, and visualized by ethidium bromide staining. The absence of each fragment in the electrophoresis pattern represented mutation in that region and was reported as Rifampin resistance (RIFr).

\subsection{Molecular Detection of Isoniazid Resistance}

In this study, KatG and InhA were considered as target genes for detecting INH resistance using specific sets of primer for PCR with the following specifications: KatGOF (5/-GCA GAT GGG GCT GAT CTA CG-3/), KatG5R (5/-ATA CGA CCT CGA TGC CGC-3/) and InhAP-15 (5/-GCG CGG TCA GTT CCA CA-3/), InhAPF2 (5/-CAC CCC GAC AAC CTA TCG-3/) for a $292 \mathrm{bp}$ and $270 \mathrm{bp}$ fragments, respectively. To detect these two types of gene mutations, PCR was performed as described for RIFr. The absence of any fragment in the electrophoresis gel was regarded as mutation in that region and reported as INHr.

\subsection{Statistical Analysis}

All data were analyzed by SPSS software version 11.5 (SPSS, Chicago, Illinois, USA). The accuracy of data was ensured by randomly selecting and checking completed questionnaires against their corresponding data in the SPSS software. Chi-squared, Fisher's exact, and t-tests were the appropriate tests used in this study. After univariate analysis, correlation of the independent variables with $\mathrm{P} \leq 0.2$ and resistance to anti-TB drugs (as dependent variables) were assessed by binary logistic regression (forward model). P values less than 0.05 were considered significant.

\subsection{Ethics Statement}

The protocol of this study was approved by Ethics Committee of the Health Policy Research Center affiliated to Shiraz university of medical sciences. All patients' data were kept confidential and all drug-resistant patients were treated and cared for accordingly.

\section{Results}

This study was comprised of 92 patients whose mean age was $45.4 \pm 15$ years with male to female ratio of 1.9 (Table 1 ). Twenty three subjects (25\%) had history of imprisonment and 14 (15.2\%) were intravenous drug users (IDUs). Nine (9.8\%) were HIV-positive and 8 (8.7\%) had diabetes mellitus (DM). Three (3.3\%) had a history of prolonged corticosteroid treatment and were on prolonged treatment course of corticosteroids and 4 (4.3\%) had cancer. In the past history, 87
(94.6\%) had cough for more than two weeks, 80 (87\%) had weight loss and 30 (33\%) exhibited hemoptysis.

Direct smear AFBs was positive in 65 cases (70.7\%) and negative in 27 (29.3\%). Culture was positive in 60 cases (66.7\%), including 57 direct smear AFBs positive and 3 direct smear AFBs negative. Forty six (50\%) had Niacin and Nitrate reduction tests positive. Seventy one (77.2\%), including 53 culture positive and 18 culture negative showed IS6110 gene in their PCR (Figure 1).

Table 1. Demographic and Risk Factors of Drug Resistant Suspected Tuberculosis Patients $(n=92)$ Referred to Tertiary Level TB Centers Affiliated With Shiraz University of Medical Sciences, South of Iran ${ }^{a}$

\begin{tabular}{|c|c|}
\hline Variable & Values \\
\hline \multicolumn{2}{|c|}{ Demographic items } \\
\hline Age, y & $45.47 \pm 15.05$ \\
\hline Median & 49 \\
\hline Minimum & 11 \\
\hline Maximum & 80 \\
\hline \multicolumn{2}{|l|}{ Gender } \\
\hline Male & $64(69.6)$ \\
\hline Female & $28(30.4)$ \\
\hline \multicolumn{2}{|l|}{ Nationality } \\
\hline Iran & $75(81.5)$ \\
\hline Afghan & $17(18.5)$ \\
\hline \multicolumn{2}{|l|}{ Marital status } \\
\hline Single & $26(28.3)$ \\
\hline Married & $66(71.7)$ \\
\hline \multicolumn{2}{|l|}{ Place of living } \\
\hline Urban & $64(69.6)$ \\
\hline Rural & $28(30.4)$ \\
\hline \multicolumn{2}{|l|}{ Job } \\
\hline Employed & $43(46.7)$ \\
\hline Unemployed & $49(53.3)$ \\
\hline \multicolumn{2}{|l|}{ Risk Factors } \\
\hline \multicolumn{2}{|c|}{ History of imprisonment } \\
\hline Yes & $23(25)$ \\
\hline No & $69(75)$ \\
\hline \multicolumn{2}{|c|}{$\begin{array}{l}\text { Prior TB or receiving Anti-TB treat- } \\
\text { ment }\end{array}$} \\
\hline Yes & $27(29.3)$ \\
\hline No & $65(70.7 \%)$ \\
\hline \multicolumn{2}{|c|}{ Intravenous drug injection(IDUs) } \\
\hline Yes & $14(15.2)$ \\
\hline No & $78(84.8)$ \\
\hline \multicolumn{2}{|l|}{ HIV infection } \\
\hline Yes & $9(9.8)$ \\
\hline No & $83(90.2)$ \\
\hline \multicolumn{2}{|c|}{ Diabetes mellitus } \\
\hline Yes & $8(8.7)$ \\
\hline No & $84(91.3)$ \\
\hline \multicolumn{2}{|c|}{ Being on corticosteroid } \\
\hline Yes & $3(3.3)$ \\
\hline No & $89(96.7)$ \\
\hline
\end{tabular}


Figure 1. PCR Amplification of $190 \mathrm{bp}$ on Agarose Gel Electrophoresis for IS6110 Detection

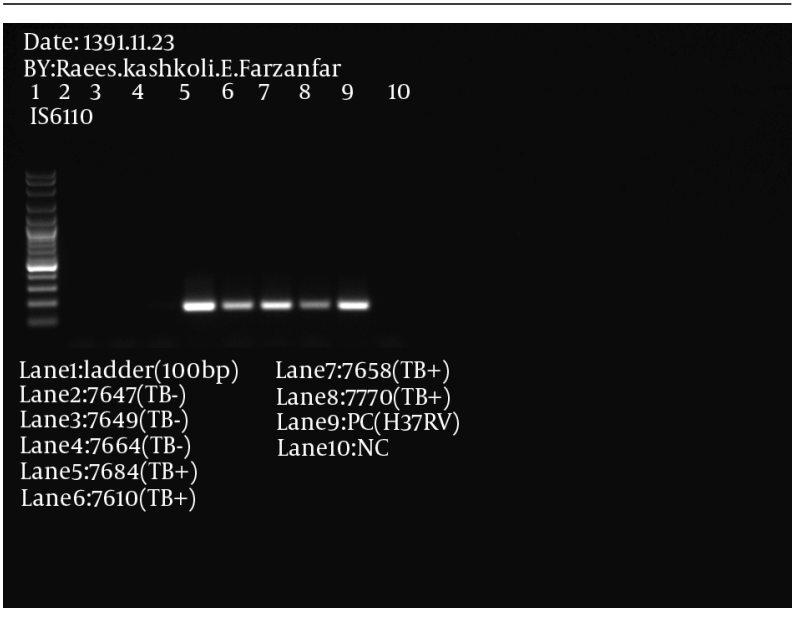

Lane 1: 100 bp ladder, Lane 2 to 8 patient samples, PC: Positive Control, NC: Negative Control.

Figure 2. Polymerase Chain Reaction Amplification of 292 bp and 270 bp on Agarose Gel Electrophoresis for KatG and InhA in Mycobactrium TB Respectively

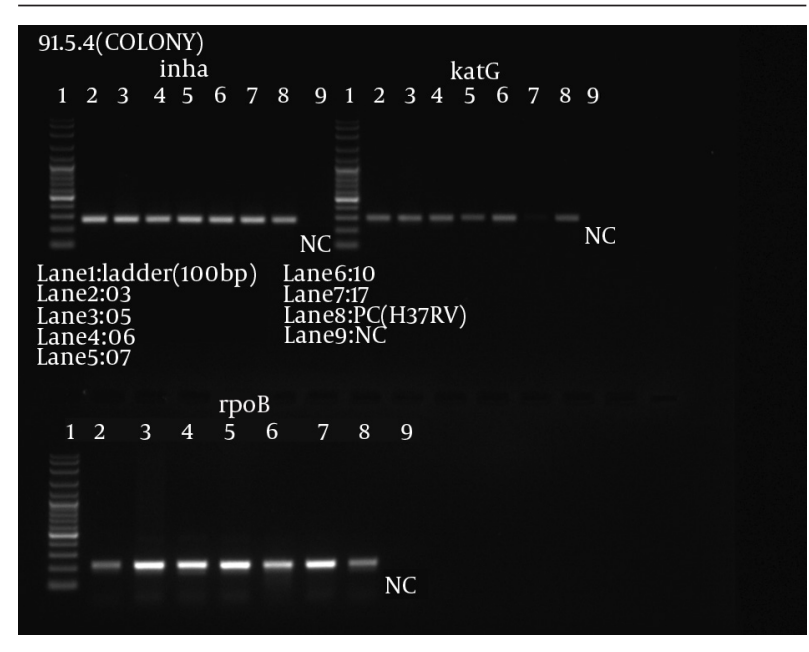

Lane 1: 100 bp ladder, Lane 2 to 7 patient samples, PC: positive Control, NC Negative Control.

Sixteen cases (17.4\%) were resistant to INH,19(20.7\%) to RIF and $24(26.1 \%)$ to both INH and RIF according to DST (Table 2). The PCR amplification showed that 3 cases (3.3\%) had KatG and 3 (3.3\%) had InhA gene mutations (Table 2, Figure 2) and $9(9.8 \%$ ) revealed both KatG and InhA mutation (Table 2).

Moreover, PCR detected rpoB gene mutation in 17 cases (18.5\%) (Table 2, Figure 3). Twenty subjects (21.7\%) harbored KatG, InhA and rpoB gene mutations (Table 2). Seventy-eight (85.7\%) patients showed positive findings compatible with $\mathrm{TB}$ in their chest X-ray. Considering different variables and various patterns of drug resistance, only patients who were resistant to INH showed a significant correlation with resistant to $\mathrm{RIF}(\mathrm{OR}=7.1, \mathrm{CI}(95 \%)=1.9-26.8, \mathrm{P}=0.004)$.
Figure 3. Polymerase Chain Reaction Amplification of 218 bp, 185 bp and 170 bp on $8 \%$ Poly Acryl Amide Gel Electrophoresis for $\operatorname{rpoB}(516,526,531)$ in Mycobactrium TB Respectively

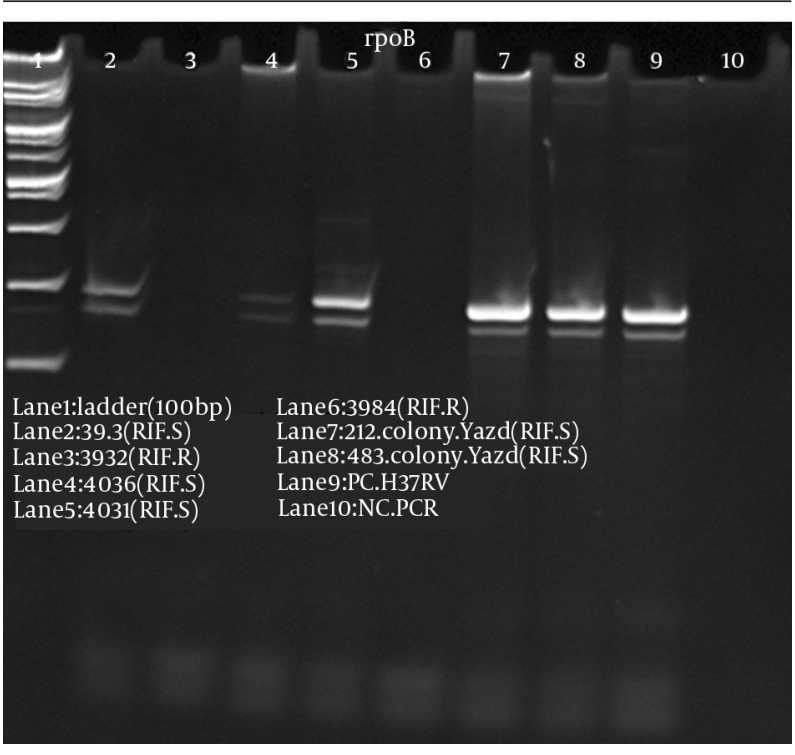

Lane 1:100 bp ladder, Lane 2 to 8 patient samples, PC: Positive Control, NC: Negative Control.

Table 2. Pattern of Drug Resistance and Gene Mutation in Drug Resistant Suspected Tuberculosis Patients $(n=92)$ Referred to Tertiary Level TB Center Affiliated With Shiraz University of Medical Sciences, South of Iran a,b

\begin{tabular}{lcr}
\hline Test Method & Test Target & Frequency \\
\hline Resistant to Isoniazid & & \\
\hline Culture & DST & $16(17.4)$ \\
\hline PCR & KatG & $3(3.3)$ \\
& inhA & $3(3.3)$ \\
& KatG/inhA & $9(9.8)$
\end{tabular}

\section{Resistant to Rifampin}

$\begin{array}{lcc}\text { Culture } & \text { DST } & 19(20.7) \\ \text { PCR } & \text { rеро B } & 17(18.5)\end{array}$

\section{Resistant to both}

Isoniazid and Rifampin

\begin{tabular}{lcc} 
Culture & DST & $24(26.1)$ \\
PCR & KatG/inhA/repo B & $20(21.7)$ \\
\hline
\end{tabular}

a Abbreviations: DST, drug susceptibility testing; PCR, polymerase chain reaction.

b Data are presented as No.(\%). 


\section{Discussion}

Tuberculosis remains one of the most challenging issues in global health. An important challenge for TB control is the spread of strains that are resistant to the most potent anti-TB drugs (26) and have been reached an emergent and epidemic proportion in many countries (27-29). This specifically applies to MDR-TB and it's relation to poor treatment outcomes and high rates of case-fatality (30). Approximately, $3.7 \%$ of recent and $20 \%$ of previously TB treated cases are afflicted with MDR-TB (31). However, less than $5 \%$ of the existing MDR-TB patients are currently being diagnosed as a result of serious laboratory capacity constraints which results in delayed MDR-TB diagnosis causes, prolonged treatments and ever-increasing costs (32). Therefore, the early and rapid detection of multidrug resistance using molecular techniques have the potential to significantly hasten the diagnosis and initiation of appropriate treatment (33).

Results of this study showed that no more than $80 \%$ of new cases of pulmonary TB patients that were diagnosed based on national TB protocol (clinical symptoms and AFB sputum smear staining) had MTB (IS6110 gene) and at least one-fifth of this group had MDR-TB. These results show that at least 1 out of every 5 patients who was routinely diagnosed and treated as a new case of pulmonary TB in our region, lacked the IS6110 gene. This finding is more than the result found by another study in Thailand which showed the lack of IS6110 gene in 10\% of patients (34) and less than $31 \%$ of the cases in India who had low to zero copy number of IS6110 gene (35) and much less than $85 \%$ of MDR-isolates in Tehran that did not have this gene (36). Therefore, the possibility of less frequent genes markers for MTB, infection by atypical mycobacteria or other diagnosis should be kept in mind in negative IS6110 gene patients $(37,38)$.

According to DST in our study, $17.4 \%, 20.7 \%$ and $26.1 \%$ of IS6110 gene positive patients were resistant to INH, RIF and both drugs, respectively. Another study in tertiary level TB center in Iran revealed that $2.6 \%, 0.9 \%$ and $6.3 \%$ of new cases compared to $3.6 \%, 3.2 \%$ and $31.7 \%$ of previously treated TB patients had INH, RIF and MDR-TB, respectively (39). In $2003-2004$, it was reported that $2.6 \%$ of new cases and $56 \%$ of previously treated TB patients that referred to the same center in Tehran had MDR-TB (40). In Saudi Arabia INH, RIF resistant cases composed of 33.8\%, and $23.5 \%$ of cases were based on DST respectively besides the presence of MDR in $20.6 \%$ of patients (41). The discrepancy of these results could be explained in terms of different settings of studies regarding population, method, location or time of study.

In this study, 24 (68\%) and 20 (62\%) cases were proved to be resistant to both INH and RIF by DST and molecular assay, respectively. This was in concordance with the result of another study in Philippines that found MDR as the most frequent resistance pattern among TB patients (42). We found that 3 (3.2\% of all patients, $9.3 \%$ of MDR patients and $20 \%$ of INH resistant cases) had KatG or InhA gene mutation and 9 (9.7\% of all patients, $28 \%$ of MDR patients and $60 \%$ of INH resistant cases) exhibited mutation in both genes by Allele Specific PCR in this study.

Another study in Tunisia (43) detected that 96.4\% and $3.6 \%$ of INH-resistant isolates had KatG and InhA gene mutations, respectively. In that study, $66 \%$ of RIF-resistant isolates yielded the $r p o B$ gene mutation, that was less than all RIF-resistant isolates in our study that were affected by this kind of gene mutation. In a study carried out in Northwest of Iran (44), it was concluded that $76 \%$ of INHresistant strains showed KatG gene mutation, which was much higher than $20 \%$ found in our study. Another molecular study performed in Egypt demonstrated that 92.3\% and $86.9 \%$ of INH and RIF resistant cases were caused by $K a t G$ and $r p o B$ genes mutation, respectively (45). In a study in Sudan, it was claimed that $12 \%$ (vs $3 / 71 ; 4 \%$ in our study) and $8 \%$ (vs 17/71; 23.9\% in our study) of MTB isolates had KatG and $r p o B$ genes mutation, respectively (45). In Ethiopia, 35 out of 260 cases (13.4\%) of smear positive pulmonary TB showed INH resistant resulting from KatG gene mutations in 33 cases (12.7\%) and InhA gene mutations in 2 cases (0.7\%) (46). In that study, 12 cases (4.6\%) had rpoB gene mutation and 13 (5\%) were MDR-TB, compared to respective frequencies of $18.4 \%$ and $21.7 \%$ in our study (46).

Among different patterns of drug resistant and factors that were assessed, only those resistant to INH showed a significant correlation with resistant to RIF (OR=7.1). A study in Tehran, Iran proved that anti-TB drug resistance had more correlation with age under 45 years, male sex, previous TB treatment, immigration, poor living conditions, and unemployment (39). In another study it was concluded that age $>65$ years was associated with higher possibility of MDR-TB (40). In Bangladesh, younger age, peri-urban locality, history of contact and tuberculosis in the past and socioeconomic status were associated with a higher rate of MDR-TB (47). A study from China showed that, inappropriate treatment, retreating, age, financial burden, poor knowledge, side effects of TB treatment and lack of service coordination were the influencing factors in the development of MDR-TB (17). A case control study in China, showed that more than three TB foci in the lung, nonstandard or irregular therapy, and adverse effects of anti-TB drugs, were associated with MDR-TB in previously treated TB patients (48). In a systematic review, it was found that MDR-TB cases in Europe were more foreign borne [odds ratio (OR) 2.46; 95\% CI 1.86 to 3.24], younger than 65 years (OR 2.53; $95 \% \mathrm{CI}$ 1.74 to 4.83 ), males (OR 1.38; 95\% CI 1.16 to 1.65 ), and HIV positives (OR 3.52; 95\% CI 2.48 to 5.01) (49). Ohmori et al concluded that TB patients in Japan who are under 80 , foreigners and retreated cases are more susceptible to TB drug resistance and especially MDR-TB (50). In California, previous anti-TB treatment was associated with MDR-TB (OR 6.57) (51). A review study revealed that previ- 
ous TB treatment and duration of treatment, immigration, alcoholism and HIV co-infection were risk factors for developing extensively drug resistant-TB (XDR-TB) (52). We found that $18.7 \%$ and $15.7 \%$ of INH and RIF resistant cases and $16.6 \%$ of MDR-TB patients were Afghan nationals, which were considerably less than $66.5 \%$ of MDR-TB patients that had the same nationality in other tertiary level TB center study in Iran (39).

The limitation of this study was that we used sets of primers that in the mutated forms could not be annealed and amplified with specific sequences, in contrast to the studies that mutation evaluation was based on sequencing methods.

Considering the increasing rate of MDR-TB, putting patients on anti-TB drugs treatment courses based on diagnosis provided only by clinical symptoms and AFB staining may cause overtreatment in at least $20 \%$ and inappropriate treatment in about $15 \%$ of patients who are suspected to have pulmonary TB. Therefore, molecular studies as a complementary diagnostic tool help decrease mentioned pitfalls and as a result would help to achieve patients' safety and their better outcome while saving human and financial resources in health care systems. We suggest strengthening the referral ТВ laboratories in Iran with molecular studies' needed infrastructures and facilities.

\section{Acknowledgements}

The researchers gratefully acknowledge the contribution of the patients referred to the TB centers affiliated to Shiraz University of Medical Sciences, all personnel of TB center for their valuable cooperation during the course of this study and department of research affiliated to Fars provincial government for financial support of this work. We also thank Sara Sedighi for improving the use of English in this manuscript.

\section{Funding/Support}

This study was funded and supported by the department of research affiliated to Fars provincial government.

\section{References}

1. Honarvar B, Odoomi N, Rezaei A, Haghighi HB, Karimi M, Hosseini A, et al. Pulmonary tuberculosis in migratory nomadic populations: the missing link in Iran's National Tuberculosis Programme. Int J Tuberc Lung Dis. 2014;18(3):272-6.

2. World Health Organization.. Global tuberculosis report 2014. 2014. Available from: http://www.who.int/tb/publications/global_report/en/.

3. Varahram M, Nasiri MJ, Farnia P, Mozafari M, Velayati AA. A retrospective analysis of isoniazid-monoresistant tuberculosis among Iranian pulmonary tuberculosis patients. Open Microbiol J. 2013;8:1-5.

4. Sotgiu G, Ferrara G, Matteelli A, Richardson MD, Centis R, RueschGerdes S, et al. Epidemiology and clinical management of XDRTB: a systematic review by TBNET. Eur Respir J. 2009;33(4):871-81.

5. Rattan A, Kalia A, Ahmad N. Multidrug-resistant mycobactrium tuberculosis: molecular perspectives. Ind JTub. 1999;46:51.
6. Sharma N, Sharma V, Singh PR, Jawed B, Babu V, Kandpal J, et al Tuberculosis and Molecular Diagnosis. 2013. Available from: https:/| www.webmedcentral.com/article_view/3992.

7. Liang L, Wu Q, Gao L, Hao Y, Liu C, Xie Y, et al. Factors contributing to the high prevalence of multidrug-resistant tuberculosis: a study from China. Thorax. 2012;67(7):632-8.

8. Chadha SS, Sharath BN, Reddy K, Jaju J, Vishnu PH, Rao S, et al Operational challenges in diagnosing multi-drug resistant TB and initiating treatment in Andhra Pradesh, India. PLoS One. 2011;6(11):e26659.

9. Storla DG, Yimer S, Bjune GA. A systematic review of delay in the diagnosis and treatment of tuberculosis. BMC Public Health. 2008;8:15.

10. Barnard M, Albert H, Coetzee G, O'Brien R, Bosman ME. Rapid molecular screening for multidrug-resistant tuberculosis in a highvolume public health laboratory in South Africa. Am J Respir Crit Care Med. 2008;177(7):787-92.

11. Gonzalo X, Drobniewski F. Is there a place for beta-lactams in the treatment of multidrug-resistant/extensively drug-resistant tuberculosis? Synergy between meropenem and amoxicillin/clavulanate. J Antimicrob Chemother. 2013;68(2):366-9.

12. Honarvar B, Lankarani KB, Odoomi N, Roudgari A, Moghadami $\mathrm{M}$, Kazerooni PA, et al. Pulmonary and latent tuberculosis screening in opiate drug users: an essential and neglected approach for harm-reduction facilities. J Addict Med. 2013;7(4):230-5.

13. Marais BJ, Raviglione MC, Donald PR, Harries AD, Kritski AL, Graham SM, et al. Scale-up of services and research priorities for diagnosis, management, and control of tuberculosis: a call to action. Lancet. 2010;375(9732):2179-91.

14. Fukushima M, Kakinuma K, Hayashi H, Nagai H, Ito K, Kawaguchi R. Detection and identification of Mycobacterium species isolates by DNA microarray. J Clin Microbiol. 2003;41(6):2605-15.

15. Gandhi NR, Moll A, Sturm AW, Pawinski R, Govender T, Lalloo U, et al. Extensively drug-resistant tuberculosis as a cause of death in patients co-infected with tuberculosis and HIV in a rural area of South Africa. Lancet. 2006;368(9547):1575-80.

16. Matteelli A, Carvalho AC, Dooley KE, Kritski A. TMC207: the first compound of a new class of potent anti-tuberculosis drugs. $\mathrm{Fu}$ ture Microbiol. 2010;5(6):849-58.

17. Miller N, Cleary T, Kraus G, Young AK, Spruill G, Hnatyszyn HJ Rapid and specific detection of Mycobacterium tuberculosis from acid-fast bacillus smear-positive respiratory specimens and BacT/ALERT MP culture bottles by using fluorogenic probes and real-time PCR. J Clin Microbiol. 2002;40(11):4143-7.

18. Patel RM. Study of production of alpha amylase secreted from par ent and mutant strain of Bacillus amyloliquefaciens and optimization of culture condition. 2013. Available from: http://hdl.handle. net/10603/9774.

19. Canetti G, Fox W, Khomenko A, Mahler HT, Menon NK, Mitchison DA, et al. Advances in techniques of testing mycobacterial drug sensitivity, and the use of sensitivity tests in tuberculosis control programmes. Bull World Health Organ. 1969;41(1):21-43.

20. Coros A, DeConno E, Derbyshire KM. IS6110, a Mycobacterium tuberculosis complex-specific insertion sequence, is also present in the genome of Mycobacterium smegmatis, suggestive of lateral gene transfer among mycobacterial species. J Bacteriol. 2008;190(9):3408-10.

21. Hillemann D, Rusch-Gerdes S, Richter E. Evaluation of the GenoType MTBDRplus assay for rifampin and isoniazid susceptibility testing of Mycobacterium tuberculosis strains and clinical specimens. J Clin Microbiol. 2007;45(8):2635-40.

22. Aragon LM, Navarro F, Heiser V, Garrigo M, Espanol M, Coll P. Rapid detection of specific gene mutations associated with isoniazid or rifampicin resistance in Mycobacterium tuberculosis clinical isolates using non-fluorescent low-density DNA microarrays. J Antimicrob Chemother. 2006;57(5):825-31.

23. Zumla A, Abubakar I, Raviglione M, Hoelscher M, Ditiu L, McHugh TD, et al. Drug-resistant tuberculosis--current dilemmas, unanswered questions, challenges, and priority needs.J Infect Dis. 2012;205 Suppl 2:S228-40.

24. Ellner JJ. The emergence of extensively drug-resistant tuberculosis: a global health crisis requiring new interventions: Part II 
scientific advances that may provide solutions. Clin Transl Sci. 2009;2(1):80-4

25. Heifets L. Mycobacteriology Laboratory. Clin Chest Med. 1997;18(1):35-53.

26. Falzon D, Jaramillo E, Schunemann HJ, Arentz M, Bauer M Bayona J, et al. WHO guidelines for the programmatic management of drug-resistant tuberculosis: 2011 update. Eur Respir J. 2011;38(3):516-28.

27. Gandhi NR, Nunn P, Dheda K, Schaaf HS, Zignol M, van Soolingen $\mathrm{D}$, et al. Multidrug-resistant and extensively drug-resistant tuberculosis: a threat to global control of tuberculosis. Lancet. 2010;375(9728):1830-43.

28. Dheda K, Warren RM, Zumla A, Grobusch MP. Extensively drugresistant tuberculosis: epidemiology and management challenges. Infect Dis Clin North Am. 2010;24(3):705-25.

29. Streicher EM, Muller B, Chihota V, Mlambo C, Tait M, Pillay M, et al. Emergence and treatment of multidrug resistant (MDR) and extensively drug-resistant (XDR) tuberculosis in South Africa. Infect Genet Evol. 2012;12(4):686-94.

30. van Soolingen D, de Haas PE, van Doorn HR, Kuijper E, Rinder H, Borgdorff MW. Mutations at amino acid position 315 of the katG gene are associated with high-level resistance to isoniazid, other drug resistance, and successful transmission of Mycobacterium tuberculosis in the Netherlands. J Infect Dis. 2000;182(6):1788-90.

31. World Health Organization.. Global incidence and prevalence of selected curable sexually transmitted infections-2008. Geneva, Switzerland: WHO; 2008. Available from: http://www.who.int/reproductivehealth/publications/rtis/stisestimates/en/.

32. World Health Organization. Molecular line probe assays for rapid screening of patients at risk of multidrug-resistant tuberculosis (MDR-TB) Policy statement. 2008. Available from: :http://www.who. int/tb/laboratory/line_probe_assays/en/.

33. O'Riordan P, Schwab U, Logan S, Cooke G, Wilkinson RJ, Davidson $\mathrm{RN}$, et al. Rapid molecular detection of rifampicin resistance facilitates early diagnosis and treatment of multi-drug resistant tuberculosis: case control study. PLoS One. 2008;3(9):e3173.

34. Idigoras P, Beristain X, Iturzaeta A, Vicente D, Perez-Trallero E. Comparison of the automated nonradiometric Bactec MGIT 960 system with Lowenstein-Jensen, Coletsos, and Middlebrook 7H11 solid media for recovery of mycobacteria. Eur J Clin Microbiol Infect Dis. 2000;19(5):350-4.

35. Chauhan DS, Sharma VD, Parashar D, Chauhan A, Singh D, Singh $\mathrm{HB}$, et al.Molecular typing of Mycobacterium tuberculosis isolates from different parts of India based on IS6110 element polymorphism using RFLP analysis. Indian J Med Res. 2007;125(4):577-81.

36. Feizabadi MM, Shahriari M, Safavi M, Gharavi S, Hamid M. Multidrug-resistant strains of Mycobacterium tuberculosis isolated from patients in Tehran belong to a genetically distinct cluster Scand J Infect Dis. 2003;35(1):47-51.

37. Farnia P, Masjedi MR, Nasiri B, Mirsaedi M, Sorooch S, Kazeampour M, et al. Instability of IS6110 patterns in multidrug-resistant strains of Mycobacterium tuberculosis. Epidemiol Infect. 2007;135(2):346-52.

38. Honarvar B, Movahedan H, Mahmoodi M, Sheikholeslami FM,
Farnia P. Mycobacterium aurum keratitis: an unusual etiology of a sight-threatening infection. Braz J Infect Dis. 2012;16(2):204-8.

39. Merza MA, Farnia P, Tabarsi P, Khazampour M, Masjedi MR, Velayati AA. Anti-tuberculosis drug resistance and associated risk factors in a tertiary level TB center in Iran: a retrospective analysis. J Infect Dev Ctries. 2011;5(7):511-9.

40. Mirsaeidi MS, Tabarsi P, Farnia P, Ebrahimi G, Morris MW, Masjedi MR, et al. Trends of drug resistant Mycobacterium tuberculosis in a tertiary tuberculosis center in Iran. Saudi Med J. 2007;28(4):544-50.

41. Asaad AM, Alqahtani JM. Primary anti-tuberculous drugs resistance of pulmonary tuberculosis in Southwestern Saudi Arabia.J Infect Public Health. 2012;5(4):281-5.

42. Gler MT, Guilatco RS, Guray CV, Tupasi TE. Screening outcomes from patients with suspected multidrug-resistant tuberculosis: lessons learned in the Philippines. Int J Tuberc Lung Dis. 2012;16(10):1326-30.

43. Ben Kahla I, Marzouk M, Henry M, Bedotto M, Cohen-Bacrie S, Ben Selma W, et al. Molecular characterisation of isoniazid- and rifampicin-resistant Mycobacterium tuberculosis in Central Tunisia. Int J Tuberc Lung Dis. 2011;15(12):1685-8.

44. Moaddab SR, Farajnia S, Kardan D, Zamanlou S, Alikhani MY. Isoniazid MIC and KatG Gene Mutations among Mycobacterium tuberculosis Isolates in Northwest of Iran. Iran J Basic Med Sci. 2011;14(6):540-5.

45. Sharaf-Eldin GS, Saeed NS, Hamid ME, Jordaan AM, Van der Spuy GD, Warren RM, et al. Molecular analysis of clinical isolates of Mycobacterium tuberculosis collected from patients with persistent disease in the Khartoum region of Sudan. J Infect. 2002;44(4):244-51

46. Tessema B, Beer J, Emmrich F, Sack U, Rodloff AC. Analysis of gene mutations associated with isoniazid, rifampicin and ethambutol resistance among Mycobacterium tuberculosis isolates from Ethiopia. BMC Infect Dis. 2012;12:37.

47. Flora MS, Amin MN, Karim MR, Afroz S, Islam S, Alam A, et al. Risk factors of multi-drug-resistant tuberculosis in Bangladeshi population: a case control study. Bangladesh Med Res Counc Bull. 2013;39(1):34-41.

48. Liu J, Wang W, Xu J, Gao M, Li C. Smear-Negative Multidrug-Resistant Tuberculosis a Significance Hidden Problem for MDR-TB Control: An Analysis of Real World Data. JTuberc Res. 2014;2014.

49. Faustini A, Hall AJ, Perucci CA. Risk factors for multidrug resistant tuberculosis in Europe: a systematic review. Thorax. 2006;61(2):158-63.

50. Ohmori M, Shimouchi A, Ito K, Uchimura K, Yoshiyama T, Mitarai S. [The background of drug-resistant tuberculosis patients on the basis of the annual report database for 2007-2009 in Japan]. Kekkaku. 2012;87(4):357-65.

51. Bojorquez I, Barnes RF, Flood J, Lopez-Gatell H, Garfein RS, Backer $\mathrm{CE}$, et al. Multidrug-resistant tuberculosis among patients in Baja California, Mexico, and Hispanic patients in California. Am J Public Health. 2013;103(7):1301-5.

52. Flor de Lima B, Tavares M. Risk factors for extensively drug-resistant tuberculosis: a review. Clin Respir J. 2014;8(1):11-23. 